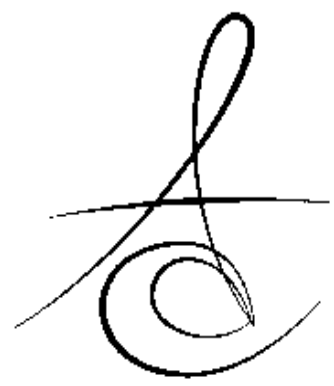

\title{
MAKSİLLER SİNÜSÜN RADYOLOJİK TANI YÖNTEMLERİNİN VE ANATOMİK LİMİTASYONLARININ TEDAVİ PLANLAMASINDA ROLÜ
}

\author{
THE ROLE OF RADIOLOGIC DIAGNOSTIC METHODS AND \\ ANATOMICAL LIMITATIONS OF MAXILLARY SINUS IN TREATMENT \\ PLANNING
}

\author{
Dr. Öğr. Üyesi Nazan KOÇAK*
}

\author{
Makale Kodu/Article code: 3199 \\ Makale Gönderilme tarihi: 13.12 .2016 \\ Kabul Tarihi: 06.03.2017
}

öz

Maksiller sinüs, üst posterior dişlerle olan anatomik yakınlığı nedeniyle cerrahi ve endodontik işlemlerde dikkat edilmesi gereken anatomik oluşumdur. Sinus elevasyonu, posterior maksiller bölgenin rehabilitasyonunda en sık kullanılan tekniktir. Sinus elevasyonu, etkili ve sonucu öngörülebilir bir tedavi protokolü olarak kabul edilse de, komplikasyonlara açık bir cerrahi yöntemdir. Bu komplikasyonlar, cerrahi işlem sırasında ya da cerrahi işlem sonrasında ortaya çıkabildiği gibi birbirleriyle bağlantılı olarak da oluşabilmektedir. Bu derlemenin amacı bu bölgede ön görülen patolojilerin tanımlanması için uygun görüntüleme yöntemleri ile birlikte bölgenin anatomik limitasyonlarının belirlenmesidir.

Anahtar Kelimeler: Anatomi, Maksiller sinüs, Radyoloji, Tanı

\section{GİRIş}

İyi bir tedavi planlamasının ilk koşulu doğru tanıdır. Doğru tanıya ulaşmak için anamnez, klinik muayene, doğru radyografi endikasyonunun konulması, radyografik incelemenin yapılması, olası hastalık yapısını belirleme, ayırıcı yorumlamaları ortaya koyma, tüm verilerin sentezlenmesi, geçici tanıyı belirleme, ilave tetkikleri belirleme ve değerlendirme, kesin tanının belirlenmesi ve tedavi planının saptanması aşamalarını içermektedir. ${ }^{1,2}$ Patolojilerin tanısında, radyolojik değerlendirme kritik önem taşımaktadır. Paranazal sinüslerin radyolojik tanı yöntemleri tedavi endikasyonlarına göre farklılık göstermekle birlikte daha az doz radyasyonla doğru tanıyı koyabilmek

\section{ABSTRACT}

Maxillary sinus is an anatomical structure that should be considered in surgery and endodontic procedures due to its anatomical proximity to the upper posterior teeth. Sinus elevation is the technique most commonly used in the rehabilitation of the posterior maxillary region. Sinus elevation is considered an effective and predictable treatment protocol, but it is an open surgical approach to complications. These complications can occur during surgery or after surgery as well as in conjunction with each other. The aim of this review is to determine the anatomic limitations of the region with appropriate imaging modalities for the identification of predictable pathologies in this area.

Key words: Anatomy, Diagnosis, Maxillary sinus, Radiology

radyoloji pratiğinde çok önemli bir yere sahiptir. Paranazal sinüslerin radyolojik tanı yöntemleri; direkt grafiler, konvansiyonel tomografi, anjiografi, ultrasonografi, manyetik rezonans, bilgisayarlı tomografi, dental volumetrik tomografi olarak belirtilmektedir., ${ }^{3,4}$ Radyolojik tanı yöntemlerinin belirlenmesinde patolojinin lokalizasyonu, yapısı ve planlanan tedavi işlemleri önemli bir yer tutar. ${ }^{3}$

\section{Radyolojik Tanı Yöntemleri}

Genel olarak radyolojik tanı yöntemlerini; direkt grafiler (Waters, Caldwell, lateral, bazal, oblik ve submentovertikal grafiler), konvansiyonel tomografi, anjiografi, ultrasonografi, Manyetik Rezonans Görüntüleme (MRG) , Bilgisayarlı Tomografiler (BT), Dental Volumetrik Tomografi (DVT) gibi yöntemler oluşturmaktadır. ${ }^{3,4}$ Her bir yöntem farklı bir tanısal yeti sunmaktadır 
ve farklı endikasyonlar için doğru seçim olabilmektedir. Son zamanlarda diş hekimliğinde DVT'lerin kullanım alanının artmasıyla maksiller sinüse ait anatomik ve patolojik yapıların ayrıntılı değerlendirilmesi mümkün hale gelmiştir.

\section{Direkt Grafiler}

Paranazal sinüslerin görüntülenmesinde kullanılan konvansiyonel teknikler; Water's, Cadwell, lateral, bazal, oblik ve submentoverteks grafileridir. Bunlar kısa zamanda görüntü elde edilebilmesi ve ekonomik olmaları nedeniyle eskiden beri öncelikli olarak istenen tetkiklerdir. Direkt grafiler sinüs içi yumuşak doku lezyonlarını, tümöral lezyonlarda kemik doku defektlerini, akut sinüzitlerde hava-sıvı seviyelerini göstermede yardımcı olmaktadır. Bunun dışında nazal kaviteyi, maksiller sinüs boşluklarını etkileyen kisti ve maksillofasiyal bölge fraktürlerini incelemek içinde yararlanılmaktadır. Çalışmalarda Water's grafisinin özellikle maksiller sinüzitin değerlendirilmesinde uygun bir tanı yöntemi olduğu bildirilmiştir. ${ }^{5,6}$

Lateral sinüs grafisi en iyi frontal sinüslerin, kısmen de sfenoid sinüsler ve maksiller kemik bölgesinin değerlendirildiği görüntüleme yöntemi iken, Cadwell grafisi ile de frontal sinüsün kemik çevreleri ve etmoid sinüsler görüntülenebilmektedir. ${ }^{7,8}$ Submentovertikal grafiyle frontal sinüsler, arka ve orta etmoid hücreler değerlendirilebilir. Ayrıca submentovertikal grafi, sfenoid sinüslerin en iyi değerlendirildiği direkt grafilerdir. Ancak direkt grafi yöntemin önemli dezavantajı normalde 3 boyutlu olan yapıların görüntülerinin, 2 boyutlu olarak elde edilmesi ve çevre yapıların incelenecek dokular üzerine süperpoze olmasıdır. ${ }^{9}$

Anatomik varyasyonlarda, osteomeatal ünite ve nazal kavitenin değerlendirilmesi gereken, cerrahi girişim planlanan olgularda, direkt grafilerin yetersiz kalmasından dolayı 3 boyutlu görüntüleme yöntemlerine ihtiyaç duyulmuştur. ${ }^{4,5}$ Konen ve ark. ${ }^{10}$ da Water's grafisinin maksiller sinüzitin teşhisinde sınırı bir tanı değeri olduğundan yerine düşük radyasyon dozuyla alınan BT'nin kullanılması gerektiğini belirtmiştir.

\section{Konvansiyonel Tomografi}

Konvansiyonel tomografi, herhangi bir vücut yapısının tek bir dilimini belirlenmiş bir düzlem üzerinde gösterebilen radyografilerdir. Bu yöntemle alınan radyografilerde 3 . boyut gözlenebilmekle beraber sadece seçilen düzlem üzerindeki doku dilimi net olarak görülebilirken, üstünde ya da altında kalan doku tabakalarının bulanık görünmesi, yöntemin önemli dezavantajıdır. ${ }^{11}$ Dolayısıyla bu yöntem sinüslerin görüntülenmesinde ve nükleer tıp çalışmalarında tercih edilmemektedir. ${ }^{12}$ Ancak konvansiyonel tomografi ile kortikal ve spongioz kemik kalınlığını ve maksiller sinüslerin sınırlarını değerlendirebilmek mümkündür. ${ }^{13}$ Kemikteki değişikliklerin değerlendirilmesinde düz grafilere göre daha hassas bir görüntüleme yöntemidir. Ancak yumuşak dokular hakkında bilgi vermez. ${ }^{14}$ Günümüzde kontrast rezolüsyonu daha iyi olan, bilgisayarlı tomografi, manyetik rezonans görüntüleme ve konik ışınlı volumetrik tomografiler tercih edilmektedir. ${ }^{3,15}$

\section{Anjiografi}

Anjiografi, paranazal sinüslerde nadir olarak görülen vasküler kökenli tümörlerin değerlendirilmesine yardımcı bir metottur. Bunun dışında kalan patolojilerin değerlendirilmesinde tercih edilmez. ${ }^{16}$

\section{Ultrasonografi}

Ultrasonografi, baş boyun hastalıklarında, tükrük bezleri ve boyuna ait patolojilerin değerlendirilmesinde kullanılan bir yöntemdir. Yüz kemiklerine ait patolojilerde, sinüs içerisindeki patolojilerin değerlendirilmesinde ise yaygın kullanımda değildir. Sinüslerde ultrasonografiyi kullanan kontrollü çalışmalar olmasına rağmen, bu yöntemin yeterli duyarlılık ve özgüllüğe sahip olmadığını gösteren çalışmalar da vardır. ${ }^{17}$ Ultrasonografi orbitaya doğru uzanım gösteren malign lezyonların yumuşak dokularını göstermede önem taşımaktadır. ${ }^{16,18}$

\section{Manyetik Rezonans}

Manyetik Rezonans Görüntüleme (MRG) temelde yumuşak doku inceleme tekniğidir. ${ }^{19}$ Paranazal sinüslerin görüntülenmesi ve hastalıklarına tanı konulmasında da önemlidir. MR görüntüleme, sinüslerin farklı planlarda çoklu kesitlerini sunar. Özellikle sinüslere ve etrafına infiltre olan neoplazmların üstün görüntülenmesini sağlar. ${ }^{20}$ Farklı dokuların detaylı değerlendirilmesini, MRG'de kullanılan değişik sinyal sekansları sağlar. Bundan dolayı yumuşak dokudaki anatomik detayların değerlendirilmesinde önemlidir. ${ }^{21}$ MRG; agresif enfeksiyonlar ve malign tümörlerin çevreye yayılımı, bazı doğumsal patolojiler, fungal sinüzit, sinüs içi kanamalar ve mukozal ödemi sinüs içi serbest sıvıdan ayırmada kullanılabilir. ${ }^{22-24}$ Yüksek kontrast rezolüsyonu sayesinde sinüs sekresyonlarını orbital yapılardan, beyin ve kitlesel lezyonlardan ayırt edebilmeye imkan sağlaması MR görüntülemenin BT'ye göre en önemli avantajıdır. Paranazal sinüslerin, neoplastik ve invaziv inflamatuar süreçlerinin değerlendirilmesinde en başarılı yöntemdir. ${ }^{20}$ 


\section{Bilgisayarlı Tomografiler}

Bilgisayarlı tomografi (BT) paranazal sinüs hastalıklarının değerlendirmesinde altın standart olarak kabul edilen görüntüleme yöntemidir. ${ }^{5,25,26}$ Ayrıca BT normal, anormal yumuşak doku ve kemik dokuların görüntülenmesinde tercih edilen ideal bir yöntemdir. Baş ve boyun bölgesindeki BT uygulamaları inflamasyon, kist, benign ve malign tümörlerin değerlendirilmesine olanak sağlar. Ayrıca maksillofasiyal, rekonstrüktif ve ortognatik cerrahi öncesi planlamalarda, dental implant uygulamalarında, travma ve TME hastalıklarında da kullanıımaktadır. 27,28

BT'nin konvansiyonel görüntüleme yöntemlerine göre avantajları şu şekilde sıralanabilir;

1. Süperpozisyon: İncelenmek istenen yapının çevredeki dokuların süperpozisyonu olmaksızın görüntülenmesine izin vermesi,

2. Yüksek kontrast rezolüsyonu: Farklı fiziksel densitelere sahip iki dokunun birbirinden daha kolay ayrılabilmesini sağlayan yüksek kontrast rezolüsyonu,

3. Distorsiyon ve magnifikasyon: Aksiyel, koronal ve sagital planda dokunun görüntülenmesine izin vermesi, distorsiyon ve magnifikasyonun olmaması,

4. Densite: Kist veya tümör varlığında densite ölçümleri ile bu lezyonların katı ya da sıvı bir yapıya sahip olduğunun belirlenmesine izin vermesi. ${ }^{11,} 27$

Dental Volumetrik Tomografi

Dental Volumetrik Tomografi (DVT) diğer adıyla konik ışınlı komputerize tomografi cihazı ilk olarak Mozzo ve ark. ${ }^{29}$ tarafından üretilmiştir. Maksiller sinüsler, diğer paranazal sinüslerden farklı olarak, küçük görüntüleme alanına sahip DVT ile görüntülenebilmektedir. Ayrıca DVT ile maksiller sinüse ait patolojilerin ve anatomik varyasyonların cerrahi işlem öncesi saptanması önem taşımaktadır. Örneğin kalın sinüs mukozası ve büyük mukozal kist varlığında gerçekleştirilen sinüs lift uygulamasının sinüzit gelişme riskini artırdığı gösterilmiştir. ${ }^{30} \mathrm{Bu}$ sebeple maksiller sinüslerin preoperatif olarak radyografik değerlendirilmesi tedavinin prognozunu olumlu yönde etkilemesi bakımından önemlidir. Paranazal bölgede ise, inflamatuar patolojilerde, fungal sinüzitlerin değerlendirilmesinde, maksiller sinüslerle diş ilişkilerinin belirlenmesinde, postoperatif değerlendirmelerde ve tümöral patolojilerin sınırlarının belirlenmesinde kullanımaktadır. ${ }^{31}$

DVT sistemin avantajları şu şekilde sıralanabilir;

1. Radyasyon: Primer $\mathrm{X}$ ışını demetinin kolimasyonu ışınlanan alanın boyutunu küçülterek radyasyon dozu seviyesini azaltır. ${ }^{31,32}$ Sinüslerin incelenme- sinde DVT'nin doz oranının BT'ye oranla daha düşük olduğu bildirilmektedir. Literatürde baş, boyun ve yüz alanlarının görüntülenmesinde kullanılan DVT'nin 4-15 adet panoramik radyografi çekimine eş değer dozda radyasyon verdiği ve efektif radyasyon dozunun BT'den yaklaşık \%85-\%98 oranında daha az olduğu belirtilmektedir. ${ }^{33,34}$ DVT cihazları farklı boyutlarda görüntüleme alanı seçme olanağına sahiptir. Böylelikle hastaya daha az radyasyon verilerek sadece görüntülenmek istenen alanın değerlendirilmesi sağlanır. ${ }^{34}$

2. Görüntü kalitesi: Bir görüntü üzerinde anatomik ve patolojik yapıların görülebilirlik düzeyi o görüntünün kalitesini tanımlar. Görüntü kalitesi; çözünürlük, gürültü ve artefakt ile ilişkilidir. DVT, BT $^{\prime}$ ye göre uzaysal çözünürlük açısından daha üstündür. DVT küçük voksel boyutu ve izotropik vokseller ile daha iyi görüntü kalitesine ve yüksek çözünürlüğe sahiptir. ${ }^{31,33,35}$ Voksel boyutu küçüldükçe uzaysal çözünürlük artmaktadır. ${ }^{31}$ DVT'nin milimetrenin altında uzaysal çözünürlüğe sahip olması nedeni ile diagnostik kalitesi daha yüksektir ve küçük yapıların ayırd edilmesinde daha başarılıdır. ${ }^{33,35} \mathrm{En}$ modern spiral BT cihazının voksel boyutu $0.35 \mathrm{~mm}$ iken DVT'de minimum voksel boyutu $0.1 \mathrm{~mm}^{\prime} \mathrm{dir} .{ }^{35}$ Ayrıca konvansiyonel $\mathrm{BT}^{\prime}$ ler anizotropiktir ve dikdörtgenler prizması şeklinde voksellere sahiptir. Öte yanda DVT cihazlarında ise vokseller izotropiktir dolayısıyla her 3 düzlemdeki boyutu aynıdır. ${ }^{33,36}$ Ancak DVT'nin kontrast rezolüsyonunun düşük olmasına bağlı olarak yumuşak doku görüntüsü zayif olmaktadır. Medikal BT cihazlarında ise kontrast rezolüsyonun yüksekliği, yumuşak doku görüntüsünün daha kaliteli olmasını sağlamaktadır. ${ }^{37}$

3. Hızlı tarama süresi: $\mathrm{X}$ ışını tüpü ve dedektör seçilen bölgenin etrafinda tek bir rotasyon yapar (180 veya 360 derece). Bu rotasyon esnasında görüntü alanında (FOV) çok sayıda (150 ile 600'den fazla) ardışık düzlemsel görüntüler elde edilir. Bu uygulama fan şeklinde X-ışını kullanan geleneksel BT'den farkııdır. BT'de her kesit ayrı bir tarama ve ayrı bir yapılandırma gerektirir. DVT taramasında ise öncelikle görüntüleme alanına dahil tüm veriler elde edilir, daha sonra elde edilen data, kesit dataya dönüştürülür. Tüm görüntülerin tek rotasyonda elde edilmesi nedeniyle tarama süresi (ortalama 10-70 s) hızlıdır. ${ }^{33,34,38}$ Görüntüleme süresinin az olması harekete bağı oluşabilecek artifaktları da en aza indirgemiş olur. ${ }^{33,34,38,39}$

4. Metalik artefaktlar: DVT görüntülerinde yoğun metalik yapılar çevresinde meydana gelen artefakt, BT görüntülerinden daha az oluşmaktadır. Bu

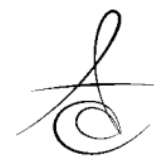


artefaktlar özellikle diş kronu, sinüs içerisinde metalik yabancı cisimler ve implant gibi cerrahi ve protetik malzemelerin etrafında belirgindir. ${ }^{31}$

5. Maliyet: DVT cihazları BT cihazlarına göre hem daha az yer kaplar hem de maliyeti daha düşüktür. ${ }^{33,38}$

\section{Anatomik Limitasyonları}

Dişsiz atrofik alveoler kret implant uygulamalarında maksiller posterior bölgedeki en önemli anatomik limitasyonlardan biridir. ${ }^{40}$ Geniş maksiller sinüs ve azalmış vestibüler derinlik ile bir araya geldiğinde gerek klasik protetik tedavi planlamalarında, gerekse implant destekli planlamalarda güçlükler ortaya çıkarmaktadır. Maksiller sinüsün hacmi yaşam boyunca doğal bir artış eğilimine sahiptir ve özellikle premolar ve molar dişler çekildiğinde, kağıt inceliğinde kemik kalacak şekilde maksiller sinüs aşağıya doğru genişleyebilir ve buna maksiller sinüsün pnömatizasyonu denir. ${ }^{41,42}$ Maksiller sinüsün pnömatizasyonu sürecinde rol oynayan faktörler; diş çekiminden sonra diş köklerinin yokluğu ve maksiller alveoler kretin atrofik rezorpsiyonudur. ${ }^{42}$ Sinüs iç basıncının çok az artması bile maksiller sinüsün hacminde belirli bir artışa neden olmaktadır. ${ }^{43}$ Alveoler kretin rezorpsiyonundan, asıl olarak sinüs membranında kısmen de alveoler kemikte bulunan osteoklastlar sorumludur. ${ }^{44}$ Geniş maksiller sinüslü, dişsiz alveoler kret olgularında kemikte rezorpsiyon meydana gelebilmektedir. Böyle durumlarda sinüs lift işlemiyle birlikte dental implant uygulamasına ihtiyaç duyulmaktadır. ${ }^{41,42}$

Günümüzde yapılan bir araştırma da, maksiller sinüs tabanına kemik greftleme operasyonlarının protetik restorasyonlar ve implant planlaması için istenen anatomik yapıyı sağladığı ve komplikasyon riskini düşürdüğü gösterilmiştir. ${ }^{43}$ Cerrahi işlemin belirlenmesinde rezidüel kemik miktarı ve genişliği, maksiller sinüs anatomisi büyük önem taşımaktadır. ${ }^{45,46}$ Sinüs lift tekniği; posterior maksillada $10 \mathrm{~mm}$ den daha az rezidüel kemik miktarı kaldığında genellikle uygulanan bir cerrahi işlem olup, 2 farklı cerrahi yaklaşım kullanımaktadır. 1) lateral pencere/direkt teknik ve 2) osteotom transkrestal/indirekt tekniktir. ${ }^{47} \mathrm{Bu}$ tekniklerin seçiminde rezidüel kemik miktarı yüksekliği önem taşımaktadır. Genellikle rezidüel kemik miktarı >5 mm'den daha fazla ise transkrestal yaklaşım uygulanırken, kemik miktarının $<5 \mathrm{~mm}$ 'den daha az olması durumunda lateral pencere yaklaşımı tercih edilmektedir. ${ }^{47,48}$

Lateral yaklaşım; maksiller sinüsün elevasyonunu içeren konvansiyonel teknik olup, maksillanın lateral tarafından, zigomatik yüzünden sinüs membra- nının elevasyonu ve graft materyalinin yerleştirilmesi işlemidir. ${ }^{45} \mathrm{Bu}$ işlem ardışık şekilde, ilk olarak flapin kaldırılması, sırasıyla sinüs lateral duvarına pencere açılması, sinüs membranının elevasyonu ve boşluk oluşturulması, ardından periosteum ile çevrili greft materyalinin yerleştirilmesi ve son olarak flapin kapatılmasından oluşmaktadır. ${ }^{46}$ Belli bir süre sonunda greft materyalinin yerini, maksillanın kemik yapılarının alması ile sonuçlanır ve bu teknikle vertikal kemik miktarı 9 mm'den daha fazla arttırılabilir. Böylece geniş kemik defektlerinde intiyaç duyulan kemik miktarı elde edilir. ${ }^{46,47} \mathrm{Bu}$ teknikte greft materyalinin yerleştirilmesi sırasında ve sonrasında komplikasyon görülme olasılığı düşüktür, ancak son derece hassas çalışılması gerekmektedir. ${ }^{45} \mathrm{Bu}$ teknikte en sık görülen komplikasyon, sinüs membran perforasyonudur. Memban perforasyonu sonucunda gelişen bakteriyel invazyon, akut ve kronik sinüs enfeksiyonuna neden olmaktadır. Ayrıca şişlik, kanama, yara bölgesinde açılma, greft materyalinin kaybolması diğer olası komplikasyonlardır. ${ }^{45}$

Transkrestal teknik ise krestal yaklaşımla osteotomlarla dental implant yerinin lateral pencere açılmaksızın osteotomi ile hazırlanmasıdır. ${ }^{45,47}$ Transkrestal teknik daha kısa zamanda gerçekleştirilen, daha az riskli bir teknik olup, postoperatif başarı daha yüksektir. Genellikle rezidüel kemik miktarı $5 \mathrm{~mm}$ den fazla ise uygulanabilir. Bu teknikle kemik yüksekliğinde 3mm'den 9 mm'ye kadar artış sağlanmaktadır. 47,48

Günümüzde komplikasyonları ve hasta rahatsızlığını azaltmak amacıyla konvansiyonel yöntemlerin dışında farklı cerrahi teknikler geliştirilmiştir. Bunlardan biri de piezoelektrik tekniğidir. Bu cerrahi girişimde düşük frekansda ultrasonik titreşimler kullanılarak, lateral duvarda bulunan kan damarlarından olabildiğince uzakta çalışılarak, yumuşak dokulara zarar vermeksizin kemik kaldırımaktadır. Bu sistemle döner alet kullanımının oluşturduğu direnç elimine edilerek, kan damarlarına ve sinüs membranına daha az zarar verilir. Bazı çalışmalarda döner alet sistemleri ile sinüs membranında perforasyon ve kanama riskinin daha düşük oranda gerçekleştiği membran üzerinde daha az fiziksel kontaktın daha az travma oluşturacağı bildirilmiştir. Bu tekniğin uygulanmasıyla sinüs membran perforasyon riskininin azalması avantaj sağlarken, işlem süresinin uzaması da dezavantaj getirmektedir. ${ }^{45,47}$

Maksiller sinüs içindeki anatomik varyasyonların da, sinüs elevasyonu sırasında membran perforasyonu riskini arttıracağı bildirilmiştir. ${ }^{49}$ Örneğin septa sayısının, kalınlığının ve uzunluğunun implant yerinin belir-

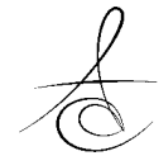


lenmesinde etkili rolü olduğu belirtilmektedir. ${ }^{50}$

Maksiller sinüs elevasyonu sırasında dikkat edilmesi gereken bir diğer anatomik oluşum ise Posterior Superior Alveoler Arter (PSAA)'dır. PSAA'nın dental dalı olan Infra Orbital Arter (IOA)'nın intraoseöz dalı ile anastamoz yapması da oldukça önemlidir. İntraoseöz anastomozun alveolar kret tepesine oldukça yakın olduğu ve maksiller sinüs periosteumu ile yakın ilişkide olduğu da bildirilmiştir. ${ }^{51,52}$ İntraoperatif ve postoperatif kanama, maksiller sinüsün cerrahisinde majör

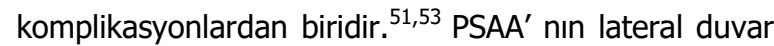
üzerindeki dağılımı, greft materyalinin iyileşmesine ve integrasyonuna katkıda bulunur. ${ }^{54}$

Elian ${ }^{55}$ ve Watanabe'de ${ }^{56}$ çalışmalarında; maksiller sinüse uygulanan cerrahi işlemler sırasında PSAA'nın zarar görüp, önemli miktarda hemorajiye neden olabileceğini bildirmişlerdir. Maksiller kemiğin nekrozu ve kanama komplikasyonlarını önlemek amacıyla cerrahi tedaviler (osteotomi, endodontik cerrahi, dental implant, yaralanma tedavileri) sırasında maksiller sinüsün vaskülarizasyonu, PSAA'nın alveolar kemikten vertikal yüksekliği ve maksiller dişlerle seviyesi hakkında bilgiye sahip olmak önemlidir. ${ }^{56,57}$ PSAA ve IOA'nın maksimum çapı $2 \mathrm{~mm}$ ile 2,7 mm arasındadır. Büyük çaplı arterler daha fazla kanama problemine yol açacağından sinüs ogmentasyonunda dikkatli olunmalıdır. ${ }^{54}$

\section{SONUÇ}

Operasyon sırasında birçok komplikasyona engel olabilmek için sinüs anatomisinin temeli iyi bilinmelidir. Kişisel varyasyonların değerlendirilebilmesi için ise ileri görüntüleme yöntemleri tercih edilmelidir. Radyolojik tanının doğru konması ve planlanan cerrahi işlemin başarısı; seçilen radyolojik yöntemin özellikleri değerlendirilerek bilinçli seçimi ile doğrudan ilgilidir.

Nazan Koçak: ORCID ID: 0000-0002-3717-2098

\section{KAYNAKLAR}

1. Özcan İ. Sistemik yaklaşımla oral diagnoz, İstanbul; Nobel Tıp Kitapevi: 2007. s:537-8.

2. Akgül $M$, Bilge $O M$, Dağistan $S$. Diş Hekimliğinde muayene ve oral diagnoz, 2.baskı, Erzurum; Gazi Üniversitesi Yayınları: 2011. s:409.

3. White SC, Pharoah MJ, Oral radiology: principles and Interpretation. 6th ed. St. Louis; Mo: Mosby/Elsevier: 2009: p:506-25.
4. Sümbüllü MA, Çakur B, Harorlı A. Antral retansiyon kistinin radyolojik tespiti; dental volumetrik tomografi ile Waters pozisyonunda çekilen paranazal sinüs radyogramın karşılaştırılması. Atatürk Üniv Diş Hek Fak Derg 2011; 21:63-7.

5. Akoğlu E, Okuyucu Ş, Karazincir S, Balcl A. Maksiller sinüs mukozal inflamatuar patolojilerinin değerlendirilmesinde Water's grafisinin değeri. KBB- Forum 2007;6:112-14.

6. Öztürk K, Cenik Z, Özer B, Eyibilen A. Çocukluk çağı sinüzitlerinde predispozan faktörler ve Water's grafisinin tanı değeri. Kulak Burun Boğaz ve Baş Boyun Cerr Derg 1999;7: 168-74.

7. Aygun N, Zinreich SJ. Radiology of the nasal cavity and paranasal sinuses. Flint PW, Lund VJ. Cummings Otolaryngol Head Neck Surg Çin, Mosby Elsevier: 2010: p: 662-4.

8. Babbel RW, Harnsberger HR, Sonken J, Hunt S. Reccuring patterns of inflamatory sinonasal diseases demonsrated on screening sinus CT. AJNR Am J Neuroradiol 1992;13:903-12.

9. MacDonald-Jankowski DS, Li TKL. Computed Tomography for Oral and Maxillofacial Surgeons. Part I: Spiral Computed Tomography. Assian J Oral Maxillofac Surg 2006;18:7-16.

10. Konen E, Faibel M, Kleinbaum Y, Wolf M, Lusky A, Hoffman $C$. et al. The value of the occipitomental (Waters') view in diagnosis of sinusitis: a comparative study with computed tomography. Clin Radiol 2000;55: 856-60.

11. Frederiksen NL. Advanced Imaging. White SC, Pharoah MJ. Oral radiology principles and Interpretation. Çin;Mosby Elsevier: 2009:p.207-210, 212.

12. Triulzi F, Zirpoli S. Imaging techniques in the diagnosis and management of rhinosinusitis in children. Pediatr Allergy Immunol 2007;18:46-9.

13. Çakur B, Sümbüllü MA, Harorlı A. Operasyon öncesi implant yerlerinin belirlenmesinde radyolojik kriterler ve radyolojik teknik seçimi. Atatürk Üniv Diş Hek Derg 2007;17:23-30.

14. Önal N. Paranasal sinüs inflamatuar hastalıklarında bilgisayarlı tomografi ve waters grafisinin karşılaştırılması. uzmanlık tezi. Sağlık Bakanlığı Göztepe Eğitim ve Araştırma Hastanesi, İstanbul. 2006

15. Kamburoğlu K. Paranazal sinüs şikayetlerinde konik ışınlı bilgisayarlı tomografi bulguları. Türkiye Klinikleri 2015; 1: 76-82. 
16. Harnsberger HR, Babbel RW, Davis LW. The major obstructive inflammattory patterns of the sinonasal seen on screening sinüs computed tomography. Semin Ultrasound CT MR. 1991;12:541-60.

17. McAlister WH, Parker BR, Kushner DC, Babcock DS, Cohen HL, Gelfand MJ, Hernandez RJ, Royal SA, Slovis TL, Smith WL, Strain JD, Strife JL, Kanda MB, Myer E, Decter RM, Moreland MS. Sinusitis in the pediatric population. Radiology 2000;215: 811 8.

18. Duarte AF, Soler RD, Zavarezzi F. Nasal endoscopy associated with paranasal sinus computerized tomography scan in the diagnosis of chronic nasal obstruction. Braz J Otorhinolaryng 2005;71:361-3.

19. Aksoy S, Ohan K. Manyetik rezonans görüntülemenin dentomaksillofasiyal bölgedeki kullanım alanları. Türkiye Klin 2015;1: 44-57.

20. Fişekçioğlu E. El-Zuki M. Manyetik rezonans görüntülemede paranazal sinüs patolojileri. Türkiye Klinikleri J Oral Maxilofac Radiol Special Topics 2015;1: 84.

21. Branstetter BF, Weissman JL. Role of MR and CT in the paranasal sinuses. Otolaryngol Clin North Am 2005;38: 1279-99.

22. Balakan T. Paranasal sinüslerin anatomik varyasyonlarının bilgisayarlı tomografi ile incelenmesi. Uzmanlık tezi, Kahraman Maraş Sütçü İmam Üniversitesi, Kahramanmaraş, 2010.

23. Akan H. Baş ve boyun radyolojisi, 1. Baskı. Ankara; Nobel Tıp Kitabevleri: 2008.

24. Mancuso AA, Hanafee WN. Computed tomography and magnetic resonance Imaging of the head and neck, 2nd ed. Baltimore; Williams\&Wilkins: 1995. p. 1-42

25. Darsey DM, English JD, Kau CH, Ellis RK, Akyalcin S. Does hyrax expansion therapy affect maxillary sinus volume? A cone-beam computed tomography report. Imaging Sci Dent 2012;42: 83-8.

26. Orhan K, Aksoy S, Bilecenoglu B, Sakul BU, Paksoy CS. Evaluation of bifid mandibular canals with cone-beam computed tomography in a Turkish adult population: A retrospective study. Surg Radiol Anat 2011;33: 501-7.

27. Altuğ HA, Ozkan A. Diagnostic imaging in oral and maxillofacial pathology. Erondu O.F. Medical Imaging 2011; 222-3.

28. Fatterpekar G, Delman B, Som P. Imaging the paranasal sinuses: Where we are and where we are going. Anat Rec 2008;291:1564-72.

29. Mozzo P, Procacci C, Tacconi A, Martini PT, Andreis IA. A new volumetric CT machine for dental imaging based on the cone-beam technique: preliminary results. European Radiology 1998;8:1558-64.

30. Shanbhag S, Karnik P, Shirke P, Shanbhag V. Association between periapical lesions and maxillary sinus mucosal thickening: a retrospective cone-beam computed tomographic study. J Endod 2013;39:853-7.

31. Hodez C, Griffaton-Taillandier C, Bensimon I. Conebeam imaging: applications in ENT. European Annals of Otorhinolaryngol Head Neck Diseases 2011;128: 65-78.

32. Scarfe WC, Farman AG. What is cone-beam CT and how does it work? Dent Clin North Am 2008;52: 707-30.

33. Scarfe WC, Farman AG, Sukovic P. Clinical applications of cone-beam computed tomography in dental practice. J Can Dent Assoc 2006;72:7580.

34. Uysal S. Konik ışınlı bilgisayarlı tomografi. Türkiye Klinikleri J Dental Sci-Special Topics 2010;1:36-43

35. Carter L, Farman AG, Geist J, Scarfe WC, Angelopoulos C, Nair MK, Hildebolt CF, Tyndall $D$, Shrout M. American academy of oral and maxillofacial radiology executive opinion statement on performing and interpreting diagnostic cone beam computed tomography. Oral Surg Oral Med Oral Pathol Oral Radiol Endod 2008;106: 561-562.

36. Terakado M, Hashimoto K, Arai $Y$, Honda M, Sekiwa T, Sato $H$. Diagnostic imaging with newly developed ortho cubic super-high resolution computed tomography (Ortho-CT). Oral Surg Oral Med Oral Pathol Oral Radiol Endod 2000;89: 509-18.

37. Mah JK, Danforth RA, Bumann A, Hatcher D. Radiation absorbed in maxillofacial imaging with a new dental computed tomography device. Oral Surg Oral Med Oral Pathol Oral Radiol Endod 2003;96: 508-13.

38. Farman AG, Scarfe WC. The basics of maxillo-facial cone beam computed tomography. Seminars in Orthodontics 2009;15: 2-13.

39. White SC. Cone-beam imaging in dentistry. Health Phys 2008;95: 628-37.

40. Aldelaimi TN, Khalil AA. Maxillary Sinus Augmentation. J Craniofac Surg 2016;27:e557-9.

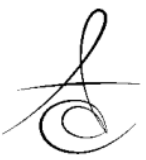


41. Chavannaz M. Maksillary sinus: Anatomy, physiology, surgery and bone grafting related to implantology eleven years of sugical experience (1979-1990). J Oral Implantol 1990; 16: 199-209.

42. Van den bergh JPA, Ten Bruggenkate CM, Krekeler G, Tuınzıng DB. Sinus floor elevation and grafting with autogenous iliac crest bone. Clin Oral Imp Res 1998;9: 429-35.

43. Mutlu M.N Sinüs tabanı yükseltilmesinde dondurulmus kurutulmus allojenik kemik greftinin kullanılması. Doktora tezi, Selçuk Üniv Saglık Bilimleri Enstitüsü, Konya, 1995

44. Davarpanah M, Martinez H, Tecucianu JF, Hage G, Lazzara R. The modified osteotome technique. Int J Periodont Res Dent 2001;21: 599-607.

45. Lozada JL, Goodacre C, Al-Ardah AJ, Garbacea A. Lateral and crestal bone planing antrostomy: a simplified surgical procedure to reduce the incidence of membrane perforation during maxillary sinus augmentation procedures. J Prosthet Dent 2011;105:147-53.

46. Kao SY, Lui MT, Cheng DH, Chen TW. Lateral trapdoor window approach with maxillary sinus membrane lifting for dental implant placement in atrophied edentulous alveolar ridge. J Chin Med Assoc 2015;78:85-8.

47. Al-Dajani M. Recent trends in sinus lift surgery and their clinical implications. Clin Implant Dent Relat Res 2016;18:204-12.

48. Del Fabbro M, Corbella S, Weinstein T, Ceresoli $\mathrm{V}$, Taschieri S. Implant survival rates after osteotome-mediated maxillary sinus augmentation: a systematic review. Clin Implant Dent Relat Res 2012; 14:e159-68.

49. Maestre-Ferrín L, Galán-Gil S, Rubio-Serrano M, Peñarrocha-Diago M, Peñarrocha-Oltra D. Maxillary sinus septa: a systematic review. Med Oral Patol Oral Cir Bucal 2010;15:e383-6.

50. González-Santana $H$, Peñarrocha-Diago $M$, Guarinos-Carbó J, Sorní-Bröker M. A study of the septa in the maxillary sinuses and the subantral alveolar processes in 30 patients. J Oral Implantol 2007;33:340-3

51. Kim JH, Ryu JS, Kim KD, Hwang SH, Moon HS. A radiographic study of the posterior superior alveolar artery. Implant Dent 2011;20:306-10.
52. Mardinger O, Abba M, Hirshberg A, Schwartz-Arad D. Prevalence, diameter and course of the maxillary intraosseous vascular canal with relation to sinus augmentation procedure: a radiographic study Int J Oral Maxillofac Surg 2007;36:735-8.

53. Hur MS, Kim JK, Hu KS, Bae HE, Park HS, Kim HJ. Clinical implications of the topography and distribution of the posterior superior alveolar artery. Craniofac Surg 2009;20:551-4.

54. Güncü GN, Yildirim YD, Wang HL, Tözüm TF. Location of posterior superior alveolar artery and evaluation of maxillary sinus anatomy with computerized tomography: A clinical study. Clin Oral Implants Res 2011;22:1164-7.

55. Elian N, Wallace S, Cho SC, Jalbout ZN, Froum S. Distribution of the maxillary artery as it relates to sinus floor augmentation. Int J Oral Maxillofac Implants 2005;20:784-7.

56. Watanabe T, Shiota M, Gao S, Imakita C, Tachikawa N, Kasugai S. Verification of posterior superior alveolar artery distribution in lateral wall of maxillary sinus by location and defect pattern. Quintessence Int 2014;45:673-8.

57. Kqiku L, Biblek R, Weigler A. H, Kqiku X, Sîadtler P. Arterial blood architecture of the maxillary sinus in dentate specimens. Basıc science. Croat Med J 2013;54:180-4.

\author{
Yazışma Adresi \\ Nazan KOÇAK, \\ Mersin Üniversitesi Diş Hek. Fak. \\ Ağız, Diş ve Çene Radyolojisi A.D Yenişehir/ \\ MERSIN \\ Tel: 05458297898 \\ e-mail: nazannkocak@gmail.com
}

